\title{
Persistent Elevations in Circulating INS DNA Among Subjects with Longstanding Type 1 Diabetes
}

\author{
Anna Neyman ${ }^{1}$, Jennifer Nelson ${ }^{1,2,3}$, Sarah Tersey ${ }^{1,2,3}$, Raghavendra G. Mirmira ${ }^{1-6}$, Carmella Evans- \\ Molina $^{2,4,5,6}$ and Emily K. Sims ${ }^{1,2,3}$ \\ ${ }^{1}$ Department of Pediatrics, ${ }^{2}$ Center for Diabetes and Metabolic Diseases, ${ }^{3}$ Herman B Wells Center for \\ Pediatric Research, ${ }^{4}$ Department of Medicine, ${ }^{5}$ Department of Biochemistry and Molecular Biology, \\ ${ }^{6}$ Department of Cellular and Integrative Physiology, Indiana University School of Medicine, Indianapolis, \\ IN 46202
}

\section{Corresponding Author:}

Emily K. Sims MD

Indiana University School of Medicine

635 Barnhill Drive

MS2031

Indianapolis, IN 46202

Tel: +1 317-944-3889

Fax: +1 317-944-3882

Email: eksims@iu.edu

Reprint requests should be addressed to Emily K. Sims.

Running Head: Serum INS DNA in longstanding T1D.

\section{Abstract}

\begin{abstract}
Aims: DNA release by dying $\beta$ cells leads to increased circulating levels of unmethylated preproinsulin (INS) DNA. Consistent with large-scale $\beta$ cell destruction, this biomarker is elevated before and at the time of type 1 diabetes (T1D) onset. We measured serum INS DNA to evaluate whether $\beta$ cells continue to undergo death in later stages of T1D.
\end{abstract}

This is the author's manuscript of the article published in final edited form as:

Neyman, A., Nelson, J., Tersey, S., Mirmira, R. G., Evans - Molina, C., \& Sims, E. K. (2018). Persistent Elevations in Circulating INS DNA Among Subjects with Longstanding Type 1 Diabetes. Diabetes, Obesity and Metabolism, 0(ja). https://doi.org/10.1111/dom.13489 
Materials and Methods: We analyzed fasting banked sera from a cross-section of 90 participants in the T1D Exchange Registry with long standing T1D (median duration of 9 years). Subjects were determined to be C-peptide (-) or (+) based on mixed-meal tolerance testing. Results were compared to 54 adult nondiabetic controls. Stimulated samples were assayed in a subset of subjects. Levels of unmethylated and methylated INS DNA were analyzed using digital droplet PCR.

Results: Fasting and stimulated circulating unmethylated INS DNA levels were increased among both Cpeptide (-) and C-peptide (+) subjects with longstanding T1D compared to non-diabetic controls $(p<0.01)$. Consistent with prior reports, unmethylated INS DNA values correlated with methylated INS DNA values, which were also elevated among T1D subjects $(p<0.001)$. There was wide variation in the effects of mixed-meal stimulation on DNA levels, with fasting values in the highest quartiles decreasing with stimulation $(p<0.05)$.

Conclusions: These results could reflect ongoing $\beta$ cell death in individuals with longstanding T1D, even in the absence of detectable C-peptide production, suggesting that therapies targeting $\beta$ cell survival could be beneficial among persons with longstanding T1D.

\section{Introduction}

Type 1 diabetes (T1D) is classically defined as autoimmune destruction of the pancreatic $\beta$ cell, leading to absolute insulin deficiency. ${ }^{1}$ By the time of presentation with clinical symptoms of hyperglycemia, individuals are thought to have lost a substantial portion of functional $\beta$ cell mass. ${ }^{2,3}$ However, recent work has identified persistent $\beta$ cells in pancreatic sections from donors with T1D years after diagnosis. ${ }^{4-}$ ${ }^{15}$ Studies have also demonstrated detectable C-peptide in a large subset of persons with longstanding T1D, suggesting the continued presence of $\beta$ cells. ${ }^{6,16,17}$ However, it is unclear whether these persistent cells continue to undergo destruction. ${ }^{5,6,13}$ Historically, studies of $\beta$ cell survival have required analysis of histologic samples from donor pancreata. However, histologic staining for $\beta$ cell death in pancreatic sections from subjects with longstanding T1D has yielded mixed results. ${ }^{5,6,13}$ These results may be related to inherent limitations of histologic analyses, including heterogeneity within an individual pancreas, and incomplete representation of the entire pancreas, given limited availability of donor pancreatic 
sections. A better understanding of the natural history of $\beta$ cell death in T1D is key to development of treatment strategies, as well as monitoring of treatment efficacy in T1D.

Because $\beta$ cells contain substantially increased amounts of unmethylated preproinsulin (INS) DNA compared to other cell populations, DNA release by dying $\beta$ cells leads to increased circulating levels of unmethylated INS DNA. ${ }^{18-23}$ Thus, in contrast to histologic analyses of $\beta$ cells, measurement of circulating unmethylated INS DNA provides the opportunity to monitor a marker of $\beta$ cell death in vivo.,15 This assay was first reported by the Herold group in 2011 , based on the idea that circulating DNA released by dying $\beta$ cells could be detected by measuring differentially methylated $\mathrm{CpG}$ dinucleotides in the insulin gene. These initial analyses utilized nested PCR to calculate a demethylation index of circulating unmethylated INS DNA relative to methylated INS DNA, which was increased in serum from mouse models of T1D as well as in human subjects with new onset T1D. ${ }^{18}$ Subsequent modifications and variations of this assay have been reported by this group and others, including analysis of CpG sites in the insulin promoter, utilization of dual probe-based detection strategies, use of droplet digital PCR for absolute quantification of copy numbers, and performance of next-generation sequencing to simultaneously analyze multiple CpG sites..$^{19,23-25}$ In addition to an increase in the ratio of circulating unmethylated to methylated INS DNA, our group previously described absolute elevations in both serum unmethylated and methylated INS DNA in pediatric subjects with new onset T1D. ${ }^{20}$ At the first follow-up visit 8 weeks after diagnosis, during the post-diagnosis honeymoon period, unmethylated INS DNA levels decreased, but methylated INS DNA levels were persistently elevated. ${ }^{20}$ While the etiology of increased methylated INS DNA has not been definitively elucidated in this population, similar increases in circulating cell free plasma DNA in patients with sepsis point to DNA release by other cells types impacted by systemic immune activation associated with T1D. ${ }^{26,27}$

Cross-sectional analyses of at-risk antibody positive family members of individuals with T1D have also demonstrated increases in unmethylated INS DNA levels, although longitudinal analysis suggested that there is considerable variability in the signal over time, with both normal and abnormal values at different time points before progression to T1D. ${ }^{22,25}$ This assay may also provide insights into therapeutic benefits of T1D treatment or prevention strategies, as unmethylated INS DNA levels were decreased in subjects who received teplizumab (anti-CD3 monoclonal antibody) compared to placebo. ${ }^{28}$ Patients with 
T1D receiving cadaveric allogenic islet transplants exhibited increased plasma unmethylated INS DNA levels in the first hours after transplant that declined during the subsequent days after the procedure, consistent with the known loss of islets that occurs during isolation and the initial transplant period. ${ }^{23}$

Although the work above has identified elevations in this novel biomarker of $\beta$ cell death before onset and at diagnosis of T1D, circulating INS DNA levels are not well characterized in later stages of T1D. ${ }^{20,22,23}$ To address this unknown, we sought to determine whether continued $\beta$ cell destruction, as reflected by serum unmethylated INS DNA, occurs in individuals with longstanding T1D participating in the T1D Exchange Registry, a clinic-based registry of individuals with T1D, followed at endocrinology centers throughout the United States. ${ }^{29}$ We quantified copies of fasting serum unmethylated INS DNA using droplet digital PCR, with a dual fluorescent probe-based multiplex assay that detects methylation or unmethylation at bp -69 of the INS gene. We predicted that T1D subjects would have increased unmethylated INS DNA, consistent with ongoing $\beta$ cell death. ${ }^{20}$ To understand relationships of $\beta$ cell death with detectable insulin production, we performed measurements in both C-peptide positive and negative subjects. Stimulated samples from a mixed-meal tolerance test (MMTT) were analyzed in a subset of individuals to assess any differences induced by carbohydrate challenge.

\section{Subjects and Methods}

\section{Subjects}

Frozen serum samples were obtained from the T1D Exchange Biobank of the T1D Exchange Registry. ${ }^{29}$ Subjects all had a clinical diagnosis of T1D made by an endocrinologist on the basis of either positive islet cell antibodies or insulin therapy started around the time of diagnosis and used continually thereafter. ${ }^{16}$ Samples were obtained from fasting and 90 minute time-points of a MMTT, as previously described. ${ }^{16,29}$ Briefly, participants were instructed to fast for 10 hours and hold rapid acting insulin within 2 hours of testing. A high protein drink was administered at $6 \mathrm{~mL} / \mathrm{kg}$ over 5 minutes, with blood samples drawn at -10, 0, 30, 60, 90, and 120 minutes. Subjects were previously classified as C-peptide negative or C-peptide positive by the T1D Exchange, based on a stimulated C-peptide response $<17 \mathrm{pmol} / \mathrm{L}$ or $\geq$ $17 \mathrm{pmol} / \mathrm{L}$ at the 90 -minute time point of the MMTT. ${ }^{16,29}$ Fasting samples were obtained from $45 \mathrm{C}$-peptide 
negative and $45 \mathrm{C}$-peptide positive individuals, and stimulated samples were obtained from 20 of the Cpeptide negative and 45 of the C-peptide positive individuals. T1D samples had been banked for 3.2-4.4 years at the time of analysis.

Banked fasting samples obtained from 54 nondiabetic adult controls were also tested.

Additionally, 90 minute serum samples from a MMTT performed as above on 12 nondiabetic healthy adult subjects were tested. Control samples had been banked for 0.5-12.9 years at the time of analysis. Given the wide sample age range in control subjects, to exclude degradation of DNA over time in older samples we looked at relationships of INS DNA values with sample age and did not observe any reduction in INS DNA signal in older samples (data not shown). Informed consent was obtained from all participants and MMTT, sample collections and biospecimen storage were approved by the Indiana University Institutional Review Board. Control and T1D subject characteristics are described in Table 1. Serum from all subjects was stored at $-80{ }^{\circ} \mathrm{C}$ until use. Researchers were blinded to subject characteristics until after assays had been performed.

\section{Laboratory Assays}

Values for HbA1c and C-peptide, as well as HLA-DRB1 typing, fasting glucose, and autoantibodies against glutamic acid decarboxylase (GAD), islet antigen 2 (IA-2), and Zinc Transporter 8

(ZnT8) were measured by the Type 1 Diabetes Exchange study as previously described. ${ }^{16,29} \mathrm{HLA}$

DRB1*04:01, DRB1*0402, DRB1*4:05, and DRB1*03:01 were considered high-risk alleles. Autoantibody testing was also performed by the Barbara Davis Autoantibody/HLA Service Center in control subjects to verify antibody negative status (Aurora, CO).

Concentrations of unmethylated and methylated INS DNA were assayed in fasting and 90 minute serum samples from all subjects. The assay for serum unmethylated and methylated INS DNA using digital droplet PCR has previously been described. ${ }^{20,30}$ Briefly, DNA was extracted from $50 \mu \mathrm{L}$ of serum using the QiaAmp DNA Blood Mini kit (Qiagen) with $5 \mu \mathrm{g}$ of poly-A DNA as carrier. Bisulfite conversion was performed using the EZ DNA Methylation-Lightning Kit (Zymo Research). Samples were analyzed by ddPCR using a dual fluorescent probe-based multiplex assay. The following primers were used: 5'GGAAATTGTAGTTTTAGTTTTTAGTTATTTGT-3' (forward); 5'-AAAACCCATCTCCCCTACCTATCA-3' 
(reverse) in combination with probes that detected methylation or unmethylation at bp -69: 5'ACCCCTACCGCCTAAC-3' (VIC); 5'-ACCCCTACCACCTAAC-3' (FAM). ddPCR was performed using ddPCR Supermix for Probes (Bio-Rad) with the following cycling conditions: $95^{\circ} \mathrm{C}$ for $10 \mathrm{~min}, 94^{\circ} \mathrm{C}$ for 30 s and $57.5^{\circ} \mathrm{C}$ for $60 \mathrm{~s}$ for 40 cycles. Droplets were analyzed by a QX200 Droplet Reader and QuantaSoft Software (Bio-Rad), from which a concentration (copies/ $\mu$ l) of methylated and unmethylated INS DNA were obtained. This final concentration was extrapolated to copies $/ \mu$ serum, then normalized to carrier DNA concentration to address differences in DNA isolation.

\section{Statistical Analysis}

To address non-normal distributions of subject variables and INS DNA values, medians and interquartile ranges (IQRs) were calculated and compared between groups using Wilcoxon Rank Sum tests or, for $>2$ groups, a Kruskal-Wallis test with Dunn's multiple comparisons test. Differences among categorical demographic variables were tested using Chi-square tests. Spearman correlations were used to measure monotonic relationships between INS DNA levels and other key variables. GraphPad Prism Version 6.00 (GraphPad Software) was used for statistical analyses of sample data. For all analyses, a p value of $\leq 0.05$ was considered significant.

\section{Results}

Baseline characteristics of the participants are shown in Table 1. Median ages of C-peptide negative and positive subjects were 34 years (IQR: $23.5,55)$ and 32 years $(20.5,47)$; and median T1D duration was 12 years $(5.5,24.5)$ and 9 years $(4,16)$, respectively. Median A1c for both groups was $7.8 \%$ (IQR 6.5-8.5 for C-peptide negative and 6.8-9.0 for C-peptide positive subjects). Diabetes comorbidities and complications for T1D subjects are detailed in Supplemental Table 1. 9 individuals with T1D were taking other medications besides insulin, which included metformin alone $(n=6)$, pramlintide acetate $(n=1)$, liraglutide $(n=1)$, and metformin + glimepiride $(n=1)$.

To test whether we could detect persistent evidence of $\beta$ cell death among individuals with longstanding T1D, we compared serum unmethylated and methylated INS DNA levels between control samples and samples from T1D Exchange subjects. As shown in Figure 1a and 1b, compared to 
controls, we observed increased fasting and stimulated unmethylated INS DNA levels among both Cpeptide negative and C-peptide positive T1D subjects, suggesting ongoing $\beta$ cell death among both groups. Consistent with previous findings of elevations at the time of T1D onset, fasting and stimulated concentrations of methylated INS DNA were also increased in both T1D groups compared to controls (Figure 1c,1d). ${ }^{20}$

Next, we tested whether mixed-meal stimulation had any effects on circulating INS DNA levels . Among all subjects, individual fasting and stimulated INS DNA levels were correlated $\left(r_{s}=0.48, p<0.001\right.$ for unmethylated INS DNA and $r_{s}=0.62, p<0.001$ for methylated INS DNA). Analysis by subject group (Figure 2) showed that most control subjects demonstrated minimal absolute changes in unmethylated or methylated INS DNA concentrations on stimulation. By contrast, both C-peptide negative and C-peptide positive T1D subjects had variable responses in INS DNA levels after MMTT, with both groups having subjects who had either increased or decreased levels after stimulation (Figure 2a-b). Differences only reached significance for methylated INS DNA in the C-peptide negative group, where fasting median methylated INS DNA concentration was reduced from 10.3 to 7.5 copies $/ \mu \mathrm{L}$ with stimulation $(\mathrm{p}<0.05)$ (Figure 2b). To understand if baseline INS DNA concentrations were linked to changes in response to MMTT stimulation, we grouped T1D subjects into quartiles based on fasting INS DNA levels. Interestingly, compared to controls, subjects with the highest fasting unmethylated and methylated INS DNA concentrations (quartile 4) had significant reductions in both unmethylated and methylated INS DNA concentrations with stimulation (Figure $2 c-d ; p<0.05$ and $p<0.01$, respectively).

To determine whether markers of islet autoimmunity were associated with increased INS DNA levels among subjects with longstanding T1D, we analyzed differences among all T1D subjects in INS DNA concentrations based on islet autoantibody positivity and high-risk HLA status. Unmethylated INS DNA concentrations tended to be higher in subjects testing positive for at least one islet autoantibody (GAD, iA2, or ZnT8) than those who did not test positive for islet autoantibodies (Figure 3a, $p=0.083$ ). No significant difference was detected in methylated INS DNA concentrations based on autoantibody status (Figure 3b). No significant differences were detected in either unmethylated or methylated INS DNA based on positivity for individual GAD, iA2, or ZnT8 antibodies. In contrast to autoantibody results, the presence of a high-risk HLA-DRB1 allele was associated with decreased unmethylated INS DNA 
concentrations compared to subjects without any high-risk alleles (Figure 3c). No difference in methylated INS DNA was detected based on HLA status (Figure 3d).

Lastly, we sought to determine which T1D subject characteristics were associated with increases in circulating unmethylated and methylated INS DNA. No differences in INS DNA concentrations were detected based on sex, racial, or ethnic groups among either control or T1D subjects (Supplemental Figure 1 and 2). Because residual C-peptide secretion decreases with longer durations of T1D, we analyzed associations between T1D duration and fasting circulating INS DNA levels (Figure 4a-b). No relationship between unmethylated INS DNA and T1D duration was detected. However, there was a weak negative correlation between methylated INS DNA concentrations and T1D duration (Figure 4b; $\left.r_{s}=0.238, p=0.02\right)$. Correlations of fasting unmethylated and methylated INS DNA levels with subject age, age at diagnosis, BMI, A1c, fasting glucose, stimulated C-peptide, and C-peptide area under the curve values were also analyzed. No significant relationships were detected between fasting DNA levels and these variables.

\section{Discussion}

Although multiple recent studies have identified detectable $\beta$ cells and insulin production among individuals with established T1D, it remains unclear whether $\beta$ cell death continues to occur during this period. ${ }^{4-6,13,16,17}$ A group of 11 subjects with longstanding T1D were previously noted to have low levels of unmethylated INS DNA, but this analysis was performed using a ratio with a less sensitive, first generation INS DNA assay, in contrast to the current analysis, which was performed with droplet digital PCR to calculate absolute copies of both unmethylated and methylated INS DNA in 90 subjects with T1D. ${ }^{28}$ Here we report the novel finding of elevated circulating unmethylated and methylated INS DNA among subjects with longstanding T1D, compared to non-diabetic adult controls. Our results suggest that $\beta$ cell death may be actively ongoing years after T1D diagnosis. Surprisingly, we detected similar elevations among subjects with and without detectable C-peptide secretion, suggesting that INS DNA concentrations may provide additional information beyond measures associated with $\beta$ cell function alone.

Elevations in unmethylated INS DNA observed in our samples were not as pronounced as those previously demonstrated in pediatric subjects with new onset T1D. ${ }^{20}$ Our observed serum unmethylated 
INS DNA values were more comparable to reported values 1 year after T1D diagnosis. ${ }^{20}$ Additionally, we did not detect a relationship between T1D duration and unmethylated INS DNA levels. These findings could reflect that only low levels of ongoing $\beta$ cell death persist after the initial post-diagnosis period, similar to slower rates of C-peptide loss observed after the first year post-diagnosis. ${ }^{31}$ Similarities in unmethylated INS DNA levels between C-peptide negative and C-peptide positive individuals could reflect a balance between higher $\beta$ cell mass in C-peptide positive individuals, but more severe disease and therefore, increased residual $\beta$ cell death in C-peptide negative individuals. Recent work has identified $\beta$ cell subpopulations that are resistant to immune attack and exhibit characteristics of dedifferentiation and dysfunctional insulin release..$^{32}$ Along these lines, our findings could also reflect a relative predominance of a persistent dysfunctional $\beta$ cell subpopulation that is relatively resistant to autoimmune destruction. Future work is indicated to determine if such a population of cells could be utilized for strategies aiming to regenerate $\beta$ cell mass in individuals with undetectable serum C-peptide. ${ }^{33}$

We also found that unmethylated INS DNA levels were actually reduced among subjects with one or two high-risk HLA-DRB1 alleles compared to subjects without high-risk HLA alleles. This finding could potentially reflect heterogeneity in T1D course, with high-risk HLA subjects having disease characterized by early $\beta$ cell destruction, resulting in reduced $\beta$ cell mass, and lower INS DNA levels in established disease. ${ }^{34}$ Analyses of longitudinal samples from the same individuals will be necessary to truly understand this relationship.

Consistent with prior work, we also detected increased methylated INS DNA levels in T1D subjects. ${ }^{20} \mathrm{~A}$ suggested source of this signal has been other cell types impacted by systemic immune activation associated with T1D. ${ }^{26,27}$ Alternatively, this finding could reflect inflammation of other islet cells or pancreatic acinar tissue, which has been reported in pancreatic sections from T1D donors. ${ }^{35}$ Further studies in other subject populations are needed to better understand the source of the methylated INS DNA signal in T1D serum. Although increases in unmethylated INS DNA levels have clearly been linked to $\beta$ cell death in both preclinical models and in human T1D, analysis of patients after pancreatectomy for chronic pancreatitis has shown a small but persistent circulating unmethylated INS DNA signal, suggesting a low-level background signal emanating from non- $\beta$ cells. ${ }^{22,27}$ Despite some overlap of T1D INS DNA levels with control values, our observed serum unmethylated INS DNA values were $\sim 3$ fold 
increased in longstanding T1D subjects compared to controls, pointing away from a non-specific background signal as the etiology of our findings.

In addition, this study is the first to report on intraindividual differences in INS DNA during fasting compared to mixed meal stimulation. Although there was significant variability in individual responses, we surprisingly observed that subjects with the highest fasting values had reductions in DNA concentrations with stimulation. We considered the possibility that this result could represent a regression to the mean, or increased variability among subjects with the highest fasting values. However, analysis of delta unmethylated INS DNA from stimulated to fasting timepoints also demonstrated that subjects with the highest stimulated values have increased values when fasting compared to stimulated timepoints (data not shown), pointing to a true phenomenon of lower stimulated INS DNA values in individuals with very elevated levels. Although repeated studies in other cohorts are needed to verify this observation, our results suggest that analysis of fasting samples may maximize observed abnormalities in INS DNA.

T1D exchange C-peptide measurements were performed using the TOSOH immunoassay, which has a limit of detection of $17 \mathrm{pmol} / \mathrm{L} .{ }^{16}$ Although more sensitive C-peptide assays exist, this assay has been widely used by multiple large-scale T1D clinical research networks. ${ }^{29,36-38}$ Furthermore, subjects with undetectable stimulated C-peptide using the TOSOH assay would likely fall into the "insulin microsecretor" category, with very low C-peptide measurements using ultrasensitive C-peptide assays. Based on this, these individuals would theoretically have smaller numbers of $\beta$ cells, and therefore lower concentrations of INS DNA if levels were closely linked to circulating C-peptide. By contrast, INS DNA levels were similar among C-peptide negative and C-peptide positive T1D subjects.

There were differences in sex and race among our controls compared to T1D subject groups. However, INS DNA concentrations were not different when compared by sex or race within either control or T1D subject groups, and values for our controls were consistent with previously reported adult control values. ${ }^{39}$ Children diagnosed with T1D have consistently been shown to have a more severe disease course than adults, with increased rates of C-peptide loss post-diagnosis. ${ }^{40-43}$ Because a significant portion of our population were diagnosed as adults, these subjects theoretically could have a larger remaining $\beta$ cell mass and therefore higher circulating unmethylated INS DNA levels. However, we were unable to detect any relationships between age of diagnosis and circulating INS DNA concentrations, 
which makes this explanation for our findings unlikely. Future studies including larger numbers of subjects diagnosed as children are indicated.

Notwithstanding these limitations, our results suggest that low levels of $\beta$ cell death may persist in subjects with longstanding T1D, independent of residual C-peptide secretion. These findings not only contribute to our understanding of the natural history of $\beta$ cell death in T1D, but provide further insight into the heterogeneous nature of T1D among affected individuals. In addition, these findings support the idea that therapeutic agents targeting $\beta$ cell destruction or $\beta$ cell proliferation could potentially be effective in improving endogenous insulin production among those with longstanding T1D and elevated circulating INS DNA levels. Longitudinal studies of changes in circulating INS DNA in T1D patients will further improve our understanding of individual patterns of $\beta$ cell death during the evolution of T1D and whether INS DNA levels are predictive of future T1D outcomes, such as diabetic complications.

\section{Acknowledgments}

This work has partially been presented in abstract form at the 2016 American Diabetes Association and Human Islet Research Network meetings, and was presented at the 2017 International Joint Meeting of Pediatric Endocrinology.

This project utilized serum samples and subject data derived from subjects participating in studies under the auspices of T1D Exchange. We wish to acknowledge the T1D Exchange Biobank and investigators and staff in the T1D Exchange Clinic Network for subject recruitment. T1D Exchange is a program of Unitio and supported by the Leona M. and Harry B. Helmsley Charitable Trust.

Other Funding Sources: This manuscript was supported by funding from NIDDK K08DK103983 to E.K.S. JDRF Strategic Research Agreement 2-SRA-2017-498-M-B to EKS, NIH 5T32DK065549-13 to A.N., UC4 DK 104166 to C.E-M., and a JDRF Strategic Research Agreement to C.E.M. This work utilized translation core services provided by the Diabetes Research Center grant P30 DK097512 to Indiana University School of Medicine. 


\section{References}

1. American Diabetes A. Standards of medical care in diabetes--2014. Diabetes Care. 2014;37 Suppl 1:S14-80.

2. Akirav E, Kushner JA, Herold KC. Beta-cell mass and type 1 diabetes: going, going, gone? Diabetes. 2008;57(11):2883-2888.

3. Insel RA, Dunne JL, Atkinson MA, et al. Staging presymptomatic type 1 diabetes: a scientific statement of JDRF, the Endocrine Society, and the American Diabetes Association. Diabetes Care. 2015;38(10):1964-1974.

4. Campbell-Thompson M, Fu A, Kaddis JS, et al. Insulitis and beta-Cell Mass in the Natural History of Type 1 Diabetes. Diabetes. 2016;65(3):719-731.

5. Meier JJ, Bhushan A, Butler AE, Rizza RA, Butler PC. Sustained beta cell apoptosis in patients with long-standing type 1 diabetes: indirect evidence for islet regeneration? Diabetologia. 2005;48(11):2221-2228.

6. Keenan HA, Sun JK, Levine J, et al. Residual insulin production and pancreatic ss-cell turnover after 50 years of diabetes: Joslin Medalist Study. Diabetes. 2010;59(11):2846-2853.

7. Butler AE, Galasso R, Meier JJ, Basu R, Rizza RA, Butler PC. Modestly increased beta cell apoptosis but no increased beta cell replication in recent-onset type 1 diabetic patients who died of diabetic ketoacidosis. Diabetologia. 2007;50(11):2323-2331.

8. Foulis AK, Liddle CN, Farquharson MA, Richmond JA, Weir RS. The histopathology of the pancreas in type 1 (insulin-dependent) diabetes mellitus: a 25-year review of deaths in patients under 20 years of age in the United Kingdom. Diabetologia. 1986;29(5):267-274.

9. Foulis AK, Stewart JA. The pancreas in recent-onset type 1 (insulin-dependent) diabetes mellitus: insulin content of islets, insulitis and associated changes in the exocrine acinar tissue. Diabetologia. 1984;26(6):456-461.

10. Kloppel G, Drenck CR, Oberholzer M, Heitz PU. Morphometric evidence for a striking B-cell reduction at the clinical onset of type 1 diabetes. Virchows Arch A Pathol Anat Histopathol. 1984;403(4):441-452.

11. Gepts W. Pathologic anatomy of the pancreas in juvenile diabetes mellitus. Diabetes. 1965;14(10):619-633.

12. Gepts W, De Mey J. Islet cell survival determined by morphology. An immunocytochemical study of the islets of Langerhans in juvenile diabetes mellitus. Diabetes. 1978;27 Suppl 1:251-261.

13. Lam CJ, Jacobson DR, Rankin MM, Cox AR, Kushner JA. beta Cells Persist in T1D Pancreata Without Evidence of Ongoing beta-Cell Turnover or Neogenesis. J Clin Endocrinol Metab. 2017;102(8):2647-2659.

14. Gianani R, Campbell-Thompson M, Sarkar SA, et al. Dimorphic histopathology of long-standing childhood-onset diabetes. Diabetologia. 2010;53(4):690-698.

15. Coppieters KT, Dotta F, Amirian N, et al. Demonstration of islet-autoreactive CD8 T cells in insulitic lesions from recent onset and long-term type 1 diabetes patients. J Exp Med. 2012;209(1):51-60.

16. Davis AK, DuBose SN, Haller MJ, et al. Prevalence of detectable C-Peptide according to age at diagnosis and duration of type 1 diabetes. Diabetes Care. 2015;38(3):476-481.

17. Oram RA, McDonald TJ, Shields BM, et al. Most People With Long-Duration Type 1 Diabetes in a Large Population-Based Study Are Insulin Microsecretors. Diabetes Care. 2015;38(2):323-328.

18. Akirav EM, Lebastchi J, Galvan EM, et al. Detection of beta cell death in diabetes using differentially methylated circulating DNA. P Natl Acad Sci USA. 2011;108(47):19018-19023.

19. Fisher MM, Perez Chumbiauca CN, Mather KJ, Mirmira RG, Tersey SA. Detection of islet betacell death in vivo by multiplex PCR analysis of differentially methylated DNA. Endocrinology. 2013;154(9):3476-3481.

20. Fisher MM, Watkins RA, Blum J, et al. Elevations in Circulating Methylated and Unmethylated Preproinsulin DNA in New-Onset Type 1 Diabetes. Diabetes. 2015;64(11):3867-3872.

21. Husseiny MI, Kuroda A, Kaye AN, Nair I, Kandeel F, Ferreri K. Development of a quantitative methylation-specific polymerase chain reaction method for monitoring beta cell death in type 1 diabetes. PLoS One. 2012;7(10):e47942. 
22. Herold KC, Usmani-Brown S, Ghazi T, et al. beta cell death and dysfunction during type 1 diabetes development in at-risk individuals. J Clin Invest. 2015;125(3):1163-1173.

23. Lehmann-Werman $\mathrm{R}$, Neiman $\mathrm{D}$, Zemmour $\mathrm{H}$, et al. Identification of tissue-specific cell death using methylation patterns of circulating DNA. Proc Natl Acad Sci U S A. 2016;113(13):E18261834.

24. Mirmira RG, Sims EK, Syed F, Evans-Molina C. Biomarkers of beta-Cell Stress and Death in Type 1 Diabetes. Curr Diab Rep. 2016;16(10):95.

25. Usmani-Brown S, Lebastchi J, Steck AK, Beam C, Herold KC, Ledizet M. Analysis of beta-cell death in type 1 diabetes by droplet digital PCR. Endocrinology. 2014;155(9):3694-3698.

26. Moreira VG, Prieto B, Rodríguez JSM, Álvarez FV. Usefulness of cell-free plasma DNA, procalcitonin and $\mathrm{C}$-reactive protein as markers of infection in febrile patients. Annals of clinical biochemistry. 2010;47(3):253-258.

27. Bellin MD, Clark P, Usmani-Brown S, et al. Unmethylated Insulin DNA Is Elevated After Total Pancreatectomy With Islet Autotransplantation: Assessment of a Novel Beta Cell Marker. Am J Transplant. 2017;17(4):1112-1118.

28. Lebastchi J, Deng S, Lebastchi AH, et al. Immune therapy and beta-cell death in type 1 diabetes. Diabetes. 2013;62(5):1676-1680.

29. Beck RW, Tamborlane WV, Bergenstal RM, et al. The T1D Exchange clinic registry. J Clin Endocrinol Metab. 2012;97(12):4383-4389.

30. Tersey SA, Nelson JB, Fisher MM, Mirmira RG. Measurement of Differentially Methylated INS DNA Species in Human Serum Samples as a Biomarker of Islet beta Cell Death. J Vis Exp. 2016(118).

31. Hao W, Gitelman S, DiMeglio LA, Boulware D, Greenbaum CJ, Type 1 Diabetes TrialNet Study G. Fall in C-Peptide During First 4 Years From Diagnosis of Type 1 Diabetes: Variable Relation to Age, HbA1c, and Insulin Dose. Diabetes care. 2016;39(10):1664-1670.

32. Rui J, Deng S, Arazi A, Perdigoto AL, Liu Z, Herold KC. $\beta$ cells that resist immunological attack develop during progression of autoimmune diabetes in NOD mice. Cell Metabolism. 2017;25(3):727-738.

33. Karakose E, Ackeifi C, Wang P, Stewart AF. Advances in drug discovery for human beta cell regeneration. Diabetologia. 2018.

34. Woittiez NJ, Roep BO. Impact of disease heterogeneity on treatment efficacy of immunotherapy in Type 1 diabetes: different shades of gray. Immunotherapy. 2015;7(2):163-174.

35. Campbell-Thompson M, Rodriguez-Calvo T, Battaglia M. Abnormalities of the Exocrine Pancreas in Type 1 Diabetes. Curr Diab Rep. 2015;15(10):79.

36. Wang L, Lovejoy NF, Faustman DL. Persistence of prolonged C-peptide production in type 1 diabetes as measured with an ultrasensitive C-peptide assay. Diabetes Care. 2012;35(3):465470.

37. Greenbaum CJ, Beam CA, Boulware D, et al. Fall in C-peptide during first 2 years from diagnosis: evidence of at least two distinct phases from composite Type 1 Diabetes TrialNet data. Diabetes. 2012;61(8):2066-2073.

38. Herold KC, Gitelman SE, Ehlers MR, et al. Teplizumab (anti-CD3 mAb) treatment preserves Cpeptide responses in patients with new-onset type 1 diabetes in a randomized controlled trial: metabolic and immunologic features at baseline identify a subgroup of responders. Diabetes. 2013;62(11):3766-3774.

39. Sims EK, Park G, Mather KJ, Mirmira RG, Liu Z, Gupta SK. Immune reconstitution in ART treated, but not untreated HIV infection, is associated with abnormal beta cell function. PLoS One. 2018;13(5):e0197080.

40. Usher-Smith JA, Thompson MJ, Sharp SJ, Walter FM. Factors associated with the presence of diabetic ketoacidosis at diagnosis of diabetes in children and young adults: a systematic review. BMJ. 2011;343:d4092.

41. Sochett EB, Daneman D, Clarson C, Ehrlich RM. Factors affecting and patterns of residual insulin secretion during the first year of type 1 (insulin-dependent) diabetes mellitus in children. Diabetologia. 1987;30(7):453-459.

42. Ludvigsson J, Carlsson A, Deli A, et al. Decline of C-peptide during the first year after diagnosis of Type 1 diabetes in children and adolescents. Diabetes Res Clin Pract. 2013;100(2):203-209. 
43. Poudel A, Savari O, Striegel DA, et al. Beta-cell destruction and preservation in childhood and adult onset type 1 diabetes. Endocrine. 2015;49(3):693-702. 
Table 1: Characteristics of Study Participants

Figure 1: Serum unmethylated and methylated INS DNA levels are increased in both C-peptide negative and C-peptide positive subjects with longstanding T1D. Fasting and stimulated unmethylated INS DNA (a-b) and methylated INS DNA (c-d) levels were measured among nondiabetic controls and in C-peptide negative (C Pep Neg) and C-peptide positive (C Pep Pos) subjects with T1D. For fasting samples, $\mathrm{n}=54$ for controls, 45 for $\mathrm{C}$ Pep Neg and 45 for $\mathrm{C}$ Pep Pos subjects. For stimulated samples, $n=12$ for controls, 20 for $C$ Pep Neg and 45 for C Pep Pos subjects. ${ }^{*} p \leq 0.05,{ }^{* *} p<0.01$, ${ }^{* * *} p<0.001$

Figure 2: Mixed-meal stimulation reduces INS DNA levels in T1D subjects with high fasting values. Individual changes in fasting and stimulated values among control, C-peptide negative (C Pep Neg) and C-peptide positive (C Pep Pos) subjects were analyzed for (a) unmethylated INS DNA and (b) methylated INS DNA. (c-d): T1D subjects were grouped into quartiles $(\mathrm{Q})$ based on fasting DNA levels and change in unmethylated (c) and methylated (d) INS DNA with stimulation was compared to controls. $\mathrm{n}=12$ for controls, 20 for C Pep Neg and 45 for C Pep Pos subjects. ${ }^{*} p \leq 0.05$, ** $p<0.01$

Figure 3: Effects of autoantibody and high-risk HLA status on unmethylated INS DNA levels. For all T1D subjects, fasting unmethylated and methylated INS DNA concentrations were plotted based on (a-b) positivity for at least one islet autoantibody as well as (c-d) the presence of one or two high-risk HLA alleles. Unmethylated INS DNA concentrations (c) and methylated INS DNA concentrations (d) based on at high-risk HLA status among all T1D subjects. $n=24$ for ab negative subjects, $n=66$ for ab positive subjects. $n=19$ for subjects without a high risk HLA, $n=71$ for subjects with one or two high risk HLAs present. ${ }^{* *} p<0.01$

Figure 4: Correlations of INS DNA levels with demographic variables. (a-b) Among all subjects, association between T1D duration and fasting unmethylated and methylated INS DNA levels. $n=90$ for all 
Table 1: Characteristics of Study Participants

\begin{tabular}{|c|c|c|c|}
\hline Variable & $\begin{array}{l}\text { Nondiabetic } \\
\text { Controls } \\
(n=54)\end{array}$ & $\begin{array}{l}\text { C-peptide } \\
\text { Negative }(n=45)\end{array}$ & $\begin{array}{l}\text { C-peptide } \\
\text { Positive } \\
(n=45)\end{array}$ \\
\hline $\begin{array}{l}\text { Age at Time of Study } \\
\text { (years) }\end{array}$ & $35(28.8,50)$ & $34(23.5,55)$ & $32(20.5,47.0)$ \\
\hline Male $(\%)^{\star}$ & $65 \%$ & $37.8 \%$ & $33.3 \%$ \\
\hline$\%$ Caucasian ${ }^{\star}$ & $46.3 \%$ & $97.8 \%$ & $82.2 \%$ \\
\hline \% Hispanic or Latino* & $1.9 \%$ & $2.2 \%$ & $8.9 \%$ \\
\hline Body Mass Index (kg/m2) & $\begin{array}{l}23.4(21.9, \\
26.6)\end{array}$ & $24.6(21.9,29.2)$ & $23.5(20.9,27.1)$ \\
\hline T1D Duration (years) & $\mathrm{n} / \mathrm{a}$ & $12(5.5,24.5)$ & $9(4,16)$ \\
\hline $\begin{array}{l}\text { Age at T1D Diagnosis } \\
\text { (years) }\end{array}$ & $\mathrm{n} / \mathrm{a}$ & $21(8.5,29)$ & $23(12,29)$ \\
\hline $\begin{array}{l}\text { Hemoglobin A1c (\%); } \\
\text { (mmol/mol) }\end{array}$ & $\mathrm{n} / \mathrm{a}$ & $\begin{array}{l}7.8 \%(6.5,8.5) \\
61.7(48,70)\end{array}$ & $\begin{array}{l}7.8 \%(6.8,9.0) \\
61.7(51,75)\end{array}$ \\
\hline $\begin{array}{l}\text { Fasting Glucose (mg/dL); } \\
(\mathrm{mmol} / \mathrm{L})\end{array}$ & $\mathrm{n} / \mathrm{a}$ & $\begin{array}{l}126(101,148.5) \\
7.0(5.6,8.2)\end{array}$ & $\begin{array}{l}137(108,165) ; 7.6 \\
(6.0,9.2)\end{array}$ \\
\hline$\%$ Antibody Positive & $\mathrm{n} / \mathrm{a}$ & $73.3 \%$ & $73.3 \%$ \\
\hline $\begin{array}{l}\text { \% Multiple Antibody } \\
\text { Positive }\end{array}$ & $\mathrm{n} / \mathrm{a}$ & $35.6 \%$ & $40 \%$ \\
\hline$\%$ GAD Antibody Positive & $\mathrm{n} / \mathrm{a}$ & $55.6 \%$ & $62.2 \%$ \\
\hline$\%$ IA-2 Antibody Positive & $n / a$ & $42.2 \%$ & $33.3 \%$ \\
\hline$\%$ ZnT8 Antibody Positive & $\mathrm{n} / \mathrm{a}$ & $13.3 \%$ & $28.9 \%$ \\
\hline $\begin{array}{l}\% \text { with } \geq 1 \text { High-Risk HLA } \\
\text { Present }\end{array}$ & $\mathrm{n} / \mathrm{a}$ & $80.0 \%$ & $77.8 \%$ \\
\hline
\end{tabular}

Results are displayed as median (interquartile range); Abbreviations: GAD-glutamic acid decarboxylase, IA-2- islet antigen 2, and ZnT8- Zinc Transporter 8; ${ }^{*} \leq \leq 0.05$ 
(a)
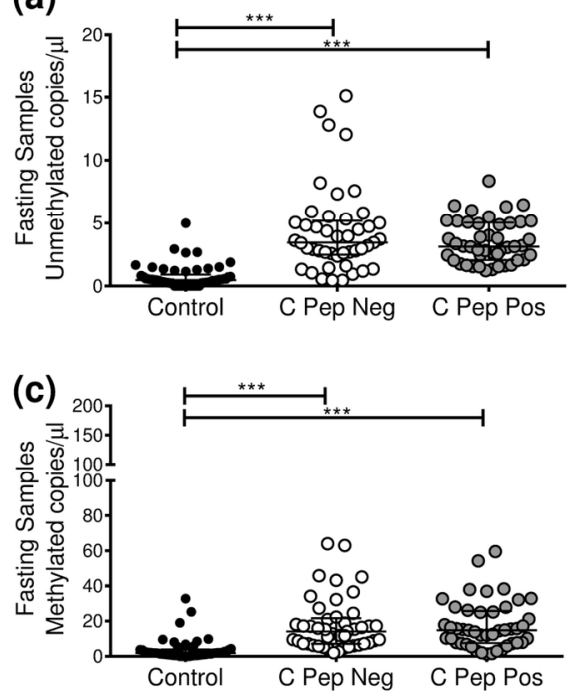

(b)
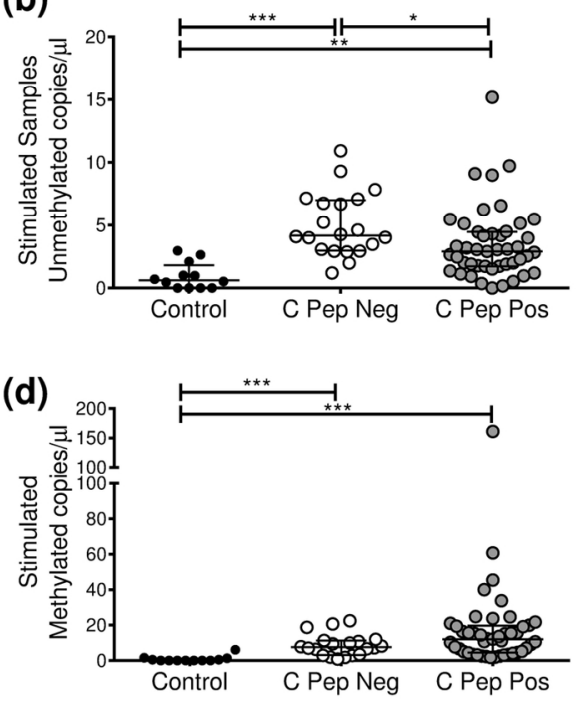

Figure 1: Serum unmethylated and methylated INS DNA levels are increased in both C-peptide negative and C-peptide positive subjects with longstanding T1D. 
(a)
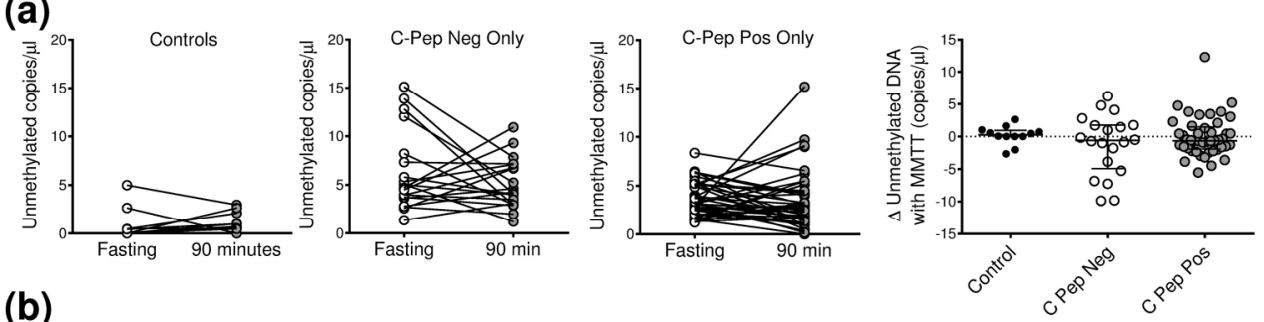

(b)
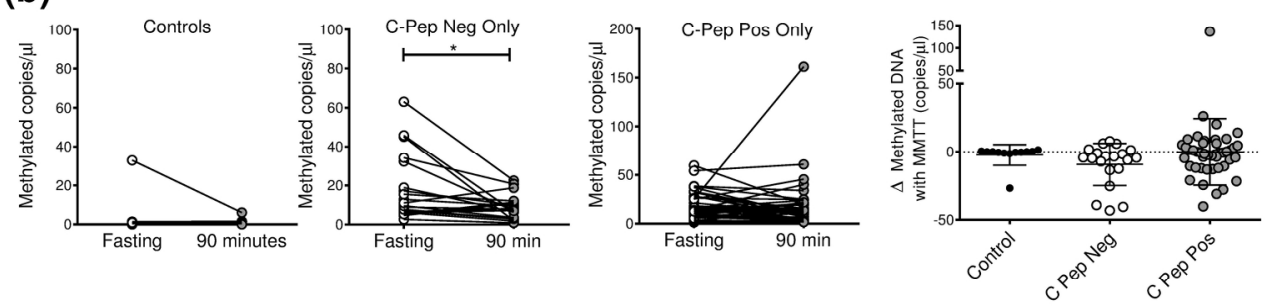

(c)

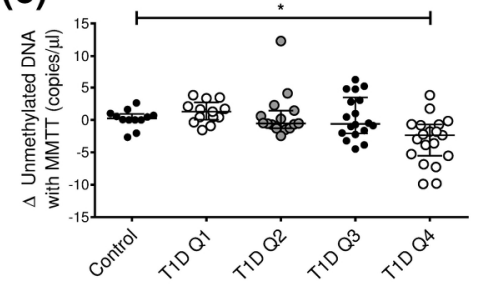

(d)

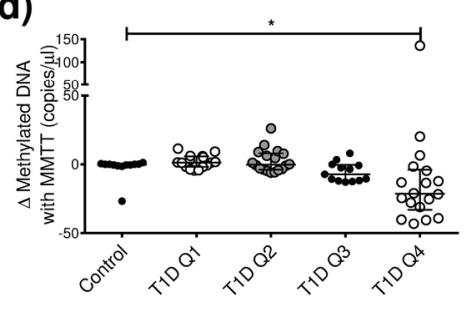

Figure 2: Mixed-meal stimulation reduces INS DNA levels in T1D subjects with high fasting values. 

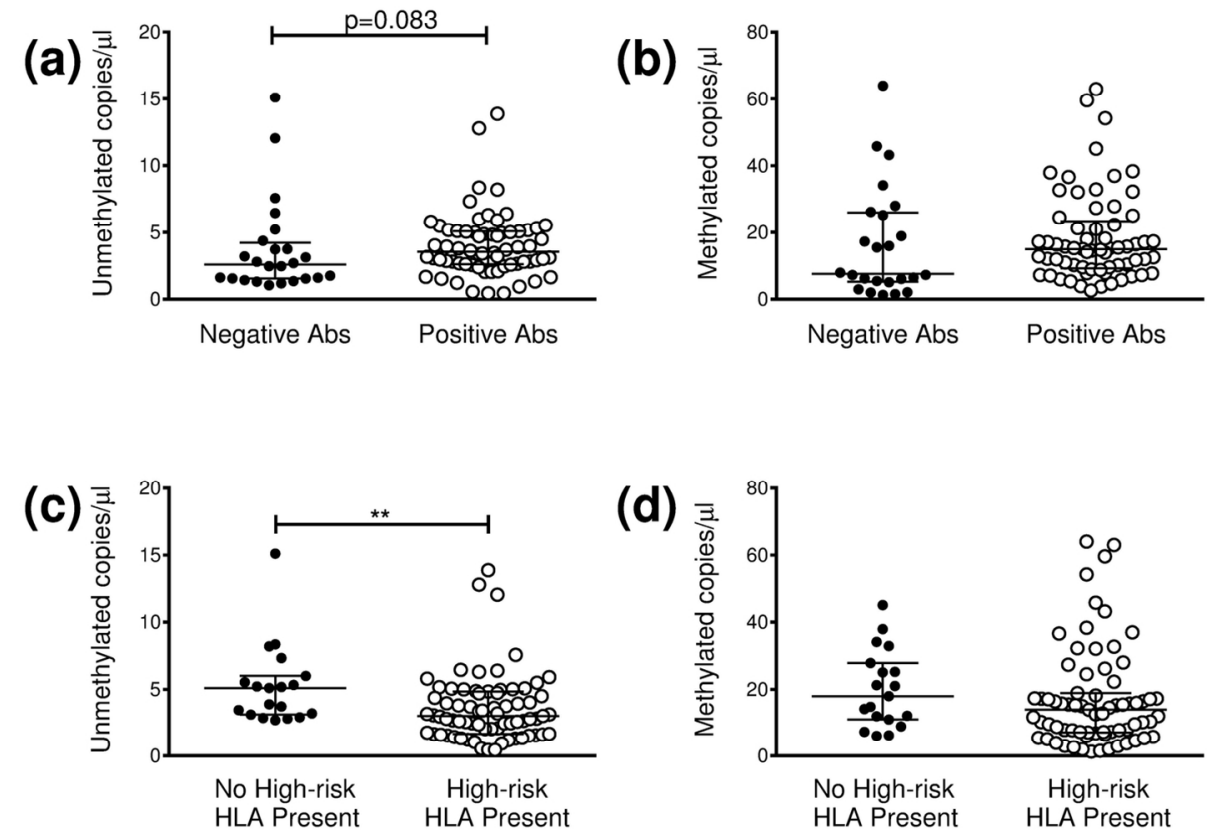

Figure 3: Effects of autoantibody and high-risk HLA status on unmethylated INS DNA levels. 

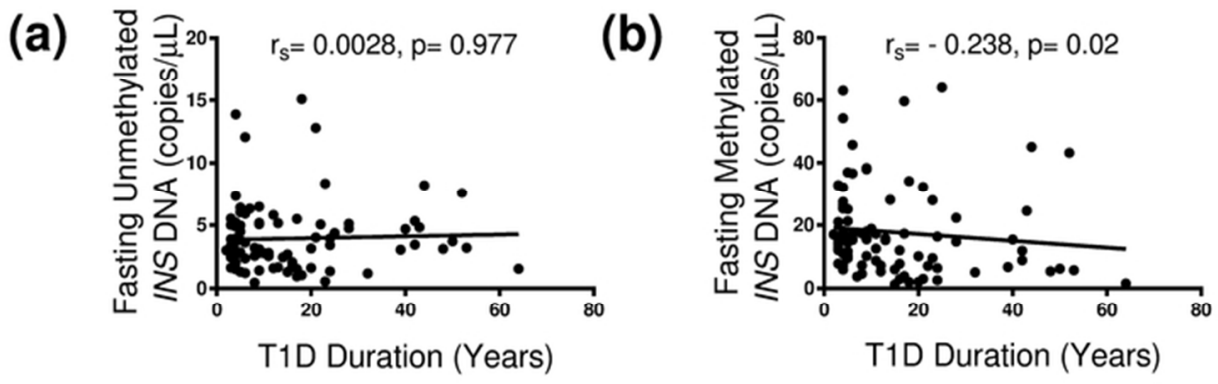

Figure 4: Correlations of INS DNA levels with demographic variables. 